\title{
Readiness to Help: How Students' Sexual Assault Awareness, Responsibility, and Action Correlate with Bystander Intervention Behavior
}

\author{
Jill C. Hoxmeier, PhD, MPH, CHES, Julia O'Connor, MPH, MSW,2 and Sarah McMahon, PhD, MSW²
}

\begin{abstract}
The transtheoretical model of change postulates that behavioral adoption is a result of individuals' readiness to change. Applied to prosocial bystander behavior, having greater sexual assault awareness, prevention responsibility, and action can explain students' readiness to intervene as bystanders. The purpose of this study was to examine the relationships between students' readiness to help (RTH) and their reported prosocial bystander behavior in five sexual assault risk situations. Data were collected from undergraduate students at a northeastern university $(n=9358)$ in 2014. Analysis of variance (ANOVA) revealed that women's mean scores for RTH subscales of awareness, taking responsibility, and action were significantly greater than men's scores. ANOVA also revealed significant differences between students who did and did not intervene in risk situations, such that those with past prosocial bystander intervention behavior reported significantly greater RTH compared with those who did not intervene. The extent to which RTH variables correlated with past prosocial bystander intervention behavior differed between men and women, as well as across the risk situations. The use of an evidence-based health behavior theory is beneficial for examining correlates of prosocial intervention and it highlights gender differences therein, as well as how readiness relates to bystander intervention behavior differently, depending on the risk situation. Implications for health promotion messaging and prevention initiatives, as well as future research, will be discussed.
\end{abstract}

Keywords: sexual assault, college students, prevention, bystander behavior, health, behavior theory

\section{Introduction}

C Ollege CAMPUSES ARE increasingly implementing bystander training programs as part of sexual violence prevention efforts (Potter and Banyard 2011). Such programs have had encouraging results; several randomized trials have demonstrated positive effects on increasing bystander intervention intentions (Banyard et al. 2007; Coker et al. 2011; Gidycz et al. 2011; McMahon et al. 2014b) and, to a lesser extent, intervention behaviors (Katz and Moore 2013; Potter and Banyard 2011). The transtheoretical model (TTM; Prochaska and DiClemente 1984) asserts that adoption of health-protective behaviors occurs when individuals move through stages and it organizes individuals according to their readiness to change.

Although the TTM has been widely used to explain differences in individuals' adoption of other health-related behaviors, its use in the field of bystander intervention behavior is limited. Banyard et al. (2010) first applied the TTM to sexual violence prevention to investigate its utility in predicting bystander behavior for participants in a training program and, later, to evaluate the effectiveness of such programs under the name of readiness to help (RTH) (see Banyard et al. 2014 for scale development). This application of the TTM contributed greatly to the field by offering a theoretical foundation for bystander training programs and subsequent evaluation of their effectiveness.

Building upon Banyard and colleagues' work, the purpose of this study is to apply the TTM to examine whether students who report past prosocial bystander intervention behavior report higher levels of RTH, compared with those who reported not to have intervened when presented with the opportunity to do so. Previous work in this area has not only assumed that students' RTH predicts their bystander intervention action (e.g., Banyard et al. 2010) but it may also be that bystander intervention action increases RTH. The present study seeks to understand the relationship between students' RTH and their bystander intervention behavior, without assuming directionality, an investigation that can uncover students' level of engagement with the

\footnotetext{
${ }^{1}$ Department of Health Sciences, Central Washington University, Ellensburg, Washington.

${ }^{2}$ Center for Violence Against Women and Children, School of Social Work, Rutgers University, New Brunswick, New Jersey.
} 
issue of campus sexual violence and potentially whether greater RTH may be reflective of previous experience with prosocial bystander intervention behavior. Exploring this association can provide insights to help shape campus prevention efforts. Students who have engaged in previous prosocial bystander behavior may be primed to take action and benefit from bystander intervention prevention programming when compared with typical students who may first require programming to increase awareness of sexual violence before receiving information on how to intervene in such situations.

\section{Theoretical framework: stages of change and RTH}

Much research has been devoted to understanding correlates of prosocial intervention intentions and behaviors (see Banyard 2011 for a review), although few studies have applied an evidence-based theoretical framework to understand the psychosocial correlates of intervention behavior relative to opportunities. Painter and colleagues (2008) stress the importance for behavior change initiatives to be theoretically based; preceding the development of those initiatives is the application of a theoretical framework aimed first at explaining behavior.

The foundational health behavior theory suggests that individuals' adoption of new health-protective behaviors, or cessation of risk behaviors, occurs as a process, and although previous use of the TTM has focused on individuals' own protective behavior, recent shifts in campus sexual violence prevention call on the community to adopt prosocial helping behaviors as a way to prevent and mitigate harms (Banyard et al. 2004). The TTM organizes individuals according to their readiness to adopt a behavior (precontemplation, contemplation, preparation, action, and maintenance; Prochaska and DiClemente 1984) and asserts that behavior change results after more advanced stages of readiness. Behavior change may stall, first, because individuals have no awareness of the health issue related to their behavior and, second, as a lack of initiation toward action even in the presence of awareness. Before individuals can adopt a new health-protective behavior, they must first be aware of the health issue related to the protective behavior and then take steps toward adoption of the new behavior.

In addition to the TTM, Banyard and colleagues' (2014) RTH measures work in conjunction with the bystander decisional model developed by Latanè and Darley (1968), which outlines a five-step model to explain individuals'

Table 1. Readiness to Help, Stage of Change, and Bystander Decision Model Schema Crosswalk

\begin{tabular}{|c|c|c|}
\hline $\begin{array}{l}\text { Readiness } \\
\text { to help }\end{array}$ & $\begin{array}{l}\text { Transtheoretical } \\
\text { Model stage of change }\end{array}$ & $\begin{array}{c}\text { Bystander } \\
\text { decisional model }\end{array}$ \\
\hline Awareness & Precontemplation & Notice the situation \\
\hline Taking & Contemplation & $\begin{array}{l}\text { Interpret risk in the } \\
\text { situation }\end{array}$ \\
\hline Responsibility & & $\begin{array}{l}\text { Take responsibility } \\
\text { for intervention }\end{array}$ \\
\hline \multirow[t]{3}{*}{ Action } & Preparation & Deciding to act \\
\hline & Action & Acting \\
\hline & Maintenance & \\
\hline
\end{tabular}

helping behavior (Table 1). Individuals must (1) notice the situation, (2) interpret the situation as one of risk, (3) take responsibility for intervening, (4) decide to intervene, and finally, (5) intervene. Although this model was not originally developed to explain bystander intervention behavior specific to sexual assault situations, Burn (2009) found utility for explaining how these five concepts can help explain potential barriers students face as bystanders to sexual assault. As Latanè and Darley assert that bystanders must first notice a situation, the TTM would characterize students with no sexual assault awareness in the precontemplation stage and thus unlikely to intervene.

Banyard and colleagues describe these individuals as having no awareness. Next, Latanè and Darley assert that individuals must take intervention responsibility. Applied to campus sexual assault, individuals must feel responsible for its prevention, best aligning with the TTM stage of contemplation. Banyard and colleagues (2014) describe these individuals as taking responsibility. Finally, Latanè and Darley describe the fourth and fifth steps in bystander intervention as deciding to act and then acting, aligning with the TTM stage of action where individuals are engaged in activities associated with behavioral change. Banyard and colleagues (2014) combine the TTM stages of preparation and action where individuals demonstrate "actively preparing for or engaged in" prevention efforts (Banyard et al. 2014, p. 105).

\section{$R T H$, prosocial bystander intervention, and gender}

In previous investigations of readiness to change, researchers postulate that higher scores of readiness are indicative of either considering or actively changing behavior (DiClemente et al. 2009; Knight et al. 2015; Matwin and Chang 2011; Usala et al. 2015). Several studies found interactions between readiness and gender, (DiClemente et al. 2009; Grossbard et al. 2016; Knight et al. 2015; Sherman et al. 2016; Usala et al. 2015), suggesting that it is critical to understand gender differences in readiness when planning prevention efforts of any type, including bystander training initiatives.

In the context of bystander intervention behavior, a small body of research indicates that there may be differences in readiness to change, or help, by gender. Cares et al. (2015) and Banyard et al. (2010) found that men were more likely to be in the precontemplation stage for sexual violence prevention, operationalized as low awareness, compared with women who were more likely to be in the contemplation stage, operationalized as taking responsibility. The latter study also found that for all students, an increase in low- and high-contemplation scores correlated with more prosocial interventions. Although Banyard and colleagues (2014) found that lower interpersonal violence awareness correlated with fewer prosocial intervention behaviors, and greater responsibility and action correlated with more prosocial intervention behaviors, gender differences were not examined and the intervention behaviors that were examined combined those for dating violence, sexual assault, and stalking risk situations.

Still, other research has found gender differences in bystander behaviors, with women reporting more prosocial intervention behavior, or fewer missed opportunities, 
compared with men (Hoxmeier, Acock, \& Flay, 2017; Hoxmeier, McMahon, O'Connor, 2017; Banyard and Moynihan, 2011; Brown et al., 2014; Burn, 2009). Scholars contend that any investigation into prosocial intervention behaviors should be measured relative to opportunities to intervene (McMahon et al. 2015), a design not used in previous examination with the TTM.

\section{The current study}

Examination of RTH variables in relation to reported prosocial intervention behaviors, outside of an experimental setting, can uncover areas of focus for campus prevention initiatives by potentially highlighting the variation of bystander experiences of students who participate in sexual violence-oriented initiatives. This study explored differences in RTH between students who did and did not intervene in sexual violence risk situations when they had the opportunity to do so, as well as any gender and situational differences therein.

Hypothesis 1: Women will report greater RTH levels compared with men.

Hypothesis 2: Students who report past prosocial intervention behavior will have greater RTH levels compared with those who reported not to have intervened when presented with the opportunity to do so.

\section{Methods}

\section{Procedures}

The authors recruited students at a large public university in the northeast in 2014 through emails, print materials, social media messages, and informational stations. The survey was online and anonymous, and all participants were eligible for randomly selected cash prizes as an incentive for participation. The university's Institutional Review Board approved all materials and procedures.

\section{Study sample}

A total of 9358 undergraduate students responded to the survey for a $30 \%$ response rate. Students who failed the attention check item $(n=677)$, provided no valid responses $(n=76)$, were duplicates $(n=6)$, provided inappropriate qualitative responses $(n=3)$, or were not between the ages of 18-24 years $(n=455)$, as well as those with missing age data $(n=203)$, were excluded from the analysis. Additionally, those who failed to identify their gender $(n=322)$ or identified a gender other than male, female, trans male, or trans female $(n=19)$ were excluded. Finally, students who were missing data on any of the RTH variables were excluded, including awareness $(n=974)$, taking responsibility $(n=976)$, and action $(n=974)$. The final sample $(n=7110)$ included 2572 students identifying as men or trans men $(36.17 \%)$ and 4538 students identifying as women or trans women (63.83\%). See Table 2 for sample demographic information.

\section{Measures}

Prosocial bystander intervention behavior. The authors used modified subscales of the Bystander Behavior ScaleRevised (McMahon et al. 2014a) to assess reported intervention opportunities and behaviors for six high-risk situations.
Table 2. SAmple Characteristics

\begin{tabular}{lc}
\hline & $\mathrm{n}(\%)$ \\
\hline Gender & \\
Men & $2558(35.97)$ \\
Trans men & $14(0.19)$ \\
Women & $4534(63.77)$ \\
Trans women & $4(0.05)$ \\
Race/ethnicity & \\
White, non-Hispanic & $3196(49.59)$ \\
Asian American & $2025(28.48)$ \\
Hispanic & $941(13.23)$ \\
African American & $560(7.88)$ \\
Other race/ethnicity & $388(5.46)$ \\
Class standing & \\
Freshman & $929(14.78)$ \\
Sophomore & $1706(27.14)$ \\
Junior & $1713(27.25)$ \\
Senior & $1939(30.84)$ \\
\hline
\end{tabular}

Totals may differ due to missing data on class standing.

To measure opportunity, the authors first asked students if they witnessed six different bystander situations since enrolling as a student at this institution (e.g., Have you seen a girl taking a drunk guy back to her room?) with a dichotomized yes/no response option. To assess students' reported intervention behaviors, when students responded yes, indicating they had the opportunity, one follow-up item asked participants, "What did you do?" Response options included (1) did nothing, it wasn't my business; (2) did nothing because I wasn't sure what to do; (3) confronted the situation directly; (4) went and got assistance from someone else; and (5) other (please specify). From these, the authors created a binary variable to test the study hypotheses - did something and did nothing-and recoded students' responses for other, where appropriate.

Readiness to help. The authors assessed students' RTH using a 12-item scale (Banyard et al. 2010, 2014; White House 2014). RTH included five items to assess students' sexual assault awareness (e.g., I don't think sexual violence is a problem at [this institution]); three items to assess students taking responsibility (e.g., Sometimes I think I should learn more about sexual violence); and four items to assess students' action to prevent sexual assault (e.g., I have recently attended a program about sexual violence). Items were measured on a 5-point rating scale (1-not at all true to 5-very much true). Items to assess awareness were recoded so that scale values were in line with the taking responsibility and action scale items. The authors created composite scores from mean values across scale items within the three subscales and named them as follows: RTH Awareness $(\alpha=0.65) ; \quad$ RTH Taking Responsibility $(\alpha=0.68)$; and RTH Action $(\alpha=0.88)$. Internal consistency for the scale as a whole was high $(\alpha=0.81)$.

\section{Results}

\section{Reported prosocial bystander intervention}

Students' bystander intervention behavior varied between risk situations (Table 3). For example, of students who 
Table 3. Students' Reported Bystander Intervention Opportunities and Response for Six Risk Situations (N=7110)

\begin{tabular}{|c|c|c|c|}
\hline \multirow{2}{*}{\multicolumn{2}{|c|}{ Students with opportunity, $\mathrm{n}$}} & \multicolumn{2}{|c|}{ Bystander intervention behavior } \\
\hline & & Did nothing, n (\%) & Did something, n (\%) \\
\hline \multicolumn{4}{|c|}{ Saw a group of students sexually intimidating/bothering someone in a parking lot or similar setting } \\
\hline Men & 173 & $82(47.40)$ & $91(52.60)$ \\
\hline Women & 438 & $249(56.85)$ & $189(43.15)$ \\
\hline Total & 611 & $331(54.17)$ & $280(45.82)$ \\
\hline \multicolumn{4}{|c|}{ Saw a girl taking a drunk guy back to her room } \\
\hline Men & 741 & $694(93.66)$ & $47(6.34)$ \\
\hline Women & 833 & $755(90.64)$ & $78(9.36)$ \\
\hline Total & 1574 & $1449(92.06)$ & $125(7.94)$ \\
\hline \multicolumn{4}{|c|}{ Saw a guy taking a drunk girl back to his room } \\
\hline Men & 926 & $779(84.13)$ & $147(15.87)$ \\
\hline Women & 1604 & $1235(77.00)$ & $369(23.00)$ \\
\hline Total & 2530 & $2014(79.60)$ & $516(20.40)$ \\
\hline \multicolumn{4}{|c|}{ Saw a girl you didn't know go to her room with a group of guys and heard her yelling for help } \\
\hline Men & 6 & $1(16.67)$ & $5(83.33)$ \\
\hline Women & 3 & $0(0)$ & $3(100.00)$ \\
\hline Total & 9 & $1(11.11)$ & $8(88.89)$ \\
\hline \multicolumn{4}{|c|}{ Heard a friend say they planned to give alcohol to someone to get sex } \\
\hline Men & 344 & $191(55.52)$ & $153(44.48)$ \\
\hline Women & 373 & $165(44.24)$ & $208(55.76)$ \\
\hline Total & 717 & $356(49.65)$ & $361(50.35)$ \\
\hline \multicolumn{4}{|c|}{ Heard rumors that a friend forced someone to have sex } \\
\hline Men & 121 & $61(50.41)$ & $60(49.59)$ \\
\hline Women & 214 & $120(56.07)$ & $94(43.93)$ \\
\hline Total & 335 & $181(54.02)$ & $154(45.98)$ \\
\hline
\end{tabular}

reported to have witnessed a group of students sexually intimidating/bothering someone in a parking lot $(n=611)$, $45.83 \%(n=280)$ of students reported they did something compared with $7.94 \%(n=125)$ of students who reported they did something for those who had the opportunity to intervene when they saw a girl taking a drunk guy back to her room $(n=1574)$. Gender differences were also observed; for example, $55.76 \%(n=208)$ of women intervened when they heard a friend say they planned to give alcohol to someone to get sex compared with $44.48 \%(n=153)$ of men. For more information on gender differences in students' opportunities and responses, see Author reference, 2017.

\section{Hypothesis 1: gender differences in students' RTH}

As hypothesized, analysis of variance (ANOVA) revealed that women reported significantly higher levels of RTH Awareness $\quad(\bar{x}=3.85$, standard deviation $[\mathrm{SD}]=0.60$;

Table 4. Gender Differences in Students' Readiness TO HelP, ANALYSIS OF VARIANCE $(N=7110)$

\begin{tabular}{llllll}
\hline & \multicolumn{3}{c}{ Students' $R T H$} & & \\
\cline { 2 - 3 } & Men, M (SD) & Women, M (SD) & F & $\eta^{2}$ \\
\hline RTH Awareness & $3.54(0.67)$ & $3.85(0.60)$ & $390.32^{* * * *}$ & 0.04 \\
RTH Taking & $3.21(0.80)$ & $3.55(0.71)$ & $356.94 * * *$ & 0.05 \\
$\begin{array}{c}\text { Responsibility } \\
\text { RTH Action }\end{array}$ & $1.99(0.85)$ & $2.07(0.90)$ & $15.18^{* *}$ & 0.01 \\
\hline
\end{tabular}

$* * p<0.01, * * * p<0.001$.

$\mathrm{RTH}$, readiness to help; SD, standard deviation. $\left.\eta^{2}=0.04\right), \quad$ RTH $\quad$ Responsibility $\quad(\bar{x}=3.55, \quad \mathrm{SD}=0.71$; $\left.\eta^{2}=0.05\right)$, and RTH Action $\left(\bar{x}=2.07, \mathrm{SD}=0.90 ; \eta^{2}=0.01\right)$ compared with men $(\bar{x}=3.54, \quad \mathrm{SD}=0.67 ; \quad \bar{x}=3.21$, $\mathrm{SD}=0.80$; and $\bar{x}=1.99, \mathrm{SD}=85$, respectively; see Table 4 ).

\section{Hypothesis 2: relationship between prosocial bystander intervention behavior and readiness}

The authors conducted separate ANOVAs for men and women to better understand gender differences in these relationships and found partial support for their hypothesis regarding the relationship between RTH variables and bystander behavior (Table 5). ANOVA revealed that among men, interveners reported significantly greater RTH Awareness, Taking Responsibility, and Action scores than noninterveners when they saw a guy taking an intoxicated girl back to their room and heard a friend say they planned to give alcohol to someone to get sex, although it should be noted that effect sizes were small.

The authors also found partial support for hypothesis 2 regarding relationships between women's RTH and prosocial bystander intervention behavior, although it should be noted that the effect sizes were small (Table 6). ANOVA revealed that among women, interveners reported significantly greater RTH Awareness, Taking Responsibility, and Action scores compared with noninterveners for each situation, with the exception of when women heard rumors that a friend had forced someone to have sex.

\section{Discussion}

The purpose of this study was to build on Banyard and colleagues' work using the TTM to understand how RTH 
Table 5. Men's Bystander Intervention Behavior and Readiness to Help, Analysis of Variance

\begin{tabular}{|c|c|c|c|c|}
\hline & \multicolumn{2}{|c|}{ Bystander intervention behavior } & \multirow[b]{2}{*}{$\mathrm{F}$} & \multirow[b]{2}{*}{$\eta^{2}$} \\
\hline & Did nothing, M (SD) & Did something, M (SD) & & \\
\hline \multicolumn{5}{|c|}{ Saw a group of students sexually intimidating/bothering someone in a parking lot or similar setting } \\
\hline RTH Awareness & $3.69(0.68)$ & $3.83(0.73)$ & 1.66 & 0.01 \\
\hline RTH Taking Responsibility & $3.30(0.84)$ & $3.50(0.78)$ & 2.66 & 0.02 \\
\hline RTH Action & $2.18(0.88)$ & $2.54(1.02)$ & $6.31 *$ & 0.04 \\
\hline \multicolumn{5}{|c|}{ Saw a girl taking a drunk guy back to her room } \\
\hline RTH Awareness & $3.57(0.68)$ & $3.65(0.67)$ & 0.66 & 0.00 \\
\hline RTH Taking Responsibility & $3.16(0.82)$ & $3.48(0.88)$ & $6.73 * *$ & 0.01 \\
\hline RTH Action & $2.03(0.88)$ & $2.49(0.99)$ & $12.15 * *$ & 0.02 \\
\hline \multicolumn{5}{|c|}{ Saw a guy taking a drunk girl back to her room } \\
\hline RTH Awareness & $3.56(0.67)$ & $3.78(0.64)$ & $13.91 * *$ & 0.01 \\
\hline RTH Taking Responsibility & $3.15(0.82)$ & $3.52(0.75)$ & $25.46 * * *$ & 0.03 \\
\hline RTH Action & $1.96(0.84)$ & $2.50(1.03)$ & $46.88 * * *$ & 0.05 \\
\hline \multicolumn{5}{|c|}{ Heard a friend say they planned to give alcohol to someone to get sex } \\
\hline RTH Awareness & $3.42(0.73)$ & $3.86(0.65)$ & $34.25 * * *$ & 0.09 \\
\hline RTH Taking Responsibility & $3.03(0.83)$ & $3.53(0.78)$ & $32.04 * * *$ & 0.06 \\
\hline RTH Action & $1.90(0.82)$ & $2.29(0.98)$ & $16.21 * *$ & 0.05 \\
\hline \multicolumn{5}{|c|}{ Heard rumors that a friend forced someone to have sex } \\
\hline RTH Awareness & $3.70(0.71)$ & $4.01(0.69)$ & $7.97 * *$ & 0.06 \\
\hline RTH Taking Responsibility & $3.30(0.85)$ & $3.48(0.81)$ & 1.51 & 0.01 \\
\hline RTH Action & $1.99(0.79)$ & $2.58(0.98)$ & $12.81 * *$ & 0.10 \\
\hline
\end{tabular}

Situation "Saw a girl you didn't know go to her room with a group of guys and heard her yelling for help" excluded due to small sample size. $* p<0.05, * * p<0.01, * * * p<0.001$.

relates to bystander behavior. These findings contribute to the understanding of students' engagement as prosocial bystanders to sexual violence by examining gender differences in $\mathrm{RTH}$, how readiness relates to intervention behavior relative to opportunity, and how these relationships vary between risk situations. The authors observed small, yet significant, gender differences in students' RTH, consistent with previous research (Banyard et al. 2010), as well as similar relationships between readiness and intervention behavior (Banyard et al. 2014). The bystander model places

Table 6. Women's Bystander Intervention Behavior and Readiness to Help, Analysis of Variance

\begin{tabular}{|c|c|c|c|c|}
\hline & \multicolumn{2}{|c|}{ Bystander intervention behavior } & \multirow[b]{2}{*}{$\mathrm{F}$} & \multirow[b]{2}{*}{$\eta^{2}$} \\
\hline & Did nothing, M (SD) & Did something, $\mathrm{M}(S D)$ & & \\
\hline \multicolumn{5}{|c|}{ Saw a group of students sexually intimidating/bothering someone in a parking lot or similar setting } \\
\hline RTH Awareness & $3.92(0.60)$ & $4.25(0.60)$ & $33.07 * * *$ & 0.07 \\
\hline RTH Taking Responsibility & $3.51(0.78)$ & $3.87(0.80)$ & $22.29 * * *$ & 0.05 \\
\hline RTH Action & $2.23(1.05)$ & $2.71(1.14)$ & $20.87 * * *$ & 0.09 \\
\hline \multicolumn{5}{|c|}{ Saw a girl taking a drunk guy back to her room } \\
\hline RTH Awareness & $3.86(0.61)$ & $4.03(0.60)$ & $5.43 *$ & 0.01 \\
\hline RTH Taking Responsibility & $3.49(0.72)$ & $3.79(0.76)$ & $12.27 * *$ & 0.01 \\
\hline RTH Action & $2.08(0.92)$ & $2.55(1.05)$ & $18.79 * * *$ & 0.05 \\
\hline \multicolumn{5}{|c|}{ Saw a guy taking a drunk girl back to her room } \\
\hline RTH Awareness & $3.87(0.58)$ & $4.08(0.61)$ & $37.77 * * *$ & 0.02 \\
\hline RTH Taking Responsibility & $3.51(0.70)$ & $3.76(0.78)$ & $35.85 * * *$ & 0.02 \\
\hline RTH Action & $2.06(0.91)$ & $2.39(1.08)$ & $33.39 * * *$ & 0.02 \\
\hline \multicolumn{5}{|c|}{ Heard a friend say they planned to give alcohol to someone to get sex } \\
\hline RTH Awareness & $3.83(0.63)$ & $4.11(0.57)$ & $19.72 * * *$ & 0.05 \\
\hline RTH Taking Responsibility & $3.52(0.76)$ & $3.80(0.72)$ & $11.91 * *$ & 0.03 \\
\hline RTH Action & $2.03(0.99)$ & $2.40(1.05)$ & $11.89 * *$ & 0.03 \\
\hline \multicolumn{5}{|c|}{ Heard rumors that a friend forced someone to have sex } \\
\hline RTH Awareness & $3.99(0.58)$ & $4.12(0.61)$ & 2.76 & 0.02 \\
\hline RTH Taking Responsibility & $3.54(0.67)$ & $3.75(0.74)$ & $4.60 *$ & 0.02 \\
\hline RTH Action & $2.19(0.92)$ & $2.61(1.23)$ & $7.94 *$ & 0.04 \\
\hline
\end{tabular}

Situation "Saw a girl you didn't know go to her room with a group of guys and heard her yelling for help" excluded due to small sample size. $* p<0.05,{ }^{* *} p<0.01, * * * p<0.001$. 
sexual violence as a community issue, aiming to engage all students in its prevention; thus, the observed gender differences in RTH, scores on RTH items indicating low levels on the later (Action) stage compared with scores for earlier stages (Awareness and Responsibility), and lack of prosocial intervention for the situations examined here ultimately demonstrate that many students remain under or unengaged.

For men and women, higher levels of RTH correlated with reports of prosocial bystander intervention behavior, although the relationships between RTH and behavior differed based on the risk situation. All three measures of readiness related to bystander intervention behavior in the most commonly reported situation (i.e., a guy taking an intoxicated girl back to his room), where the majority of bystanders reported no intervention.

Previous research demonstrates that campus assaults are more likely to involve alcohol (Abbey et al. 1996; Cantor et al. 2015), and the intersection of alcohol and sex may normalize these situations (Vander Ven 2011) and challenges the ability to recognize risk (Katz et al. 2015; Pugh et al. 2016). Those who intervene may have heightened awareness of sexual violence as a campus issue, sense of responsibility for its prevention, and current, or recent, participation in sexual violence-oriented activities where the relationship between alcohol and assault has been clarified. The relationship between RTH and bystander intervention behavior is perhaps unsurprising given the evidence supporting the use of the TTM to explain behavior, yet the relationships found here are not necessarily causal and do not assume that readiness precedes intervention behavior. As such, there are important implications for the planning of campus prevention initiatives as well as future research in this area.

Banyard and colleagues (2010) found moving students toward later stages of readiness increased intervention willingness in an experimental setting, while Banyard and colleagues (2014) found that readiness correlated with intervention behavior. It could be, however, that RTH results from experience as a prosocial bystander, whereby past intervention behavior propels students to more active engagement in sexual violence prevention initiatives, as operationalized by the RTH Action stage. Thus, participants in intervention training may bring varying levels of readiness to the program (Banyard et al. 2010), the strategies of which could be more effective when tailored to individuals' stage of readiness (Prochaska and DiClemente 1986).

As bystander training becomes widespread, it is vital to consider the range of awareness students possess regarding sexual assault, how they envision their role in prevention, and whether they have previous exposure to prevention initiatives. Strategies used to heighten awareness about the issue of campus sexual violence can, and should, be different from those aimed to increase prevention responsibility as well as to change and sustain bystander intervention behavior. From a TTM perspective, students with limited awareness about campus sexual assault may not be ready to participate in bystander training programs.

Echoing the assertions of scholars, while it is imperative that college campuses implement prevention programming, their provision is not enough (Banyard et al. 2004; Edwards et al. 2002; Potter et al. 2000) if prevention efforts do not convey a consistent message receptive to a critical mass. By inquiring into students' past intervention behavior and cur- rent $\mathrm{RTH}$, the findings here suggest that students inclined to engage in violence prevention initiatives, such as bystander training programs, may be those with more past prosocial intervention behavior experience. One implication of this could be that participants in bystander training programs may already be more engaged than those who opt not to participate in training or activities, and students who do not intervene - the majority of students in this sample-are reluctant to participate in the very programs aimed to increase prosocial bystander behavior.

In light of this, although the authors have applied the TTM to uncover differences in readiness between interveners and noninterveners, applying the theory to the promotion of bystander training programs could prove beneficial for increasing students' participation in such programs and/or reinforcing the content provided in many initiatives.

For instance, consciousness raising, dramatic relief, and environmental reevaluation are three processes of change of the TTM aimed to increase awareness and responsibility (Banyard et al. 2010; Prochaska and DiClemente 1986) that could provide the basis of health communication messaging. Consciousness-raising messages could be specific to the common features of campus sexual assault (between acquaintances/involving alcohol) and the institution's provision of prevention programming (bystander training). Based on dramatic relief, messaging may focus on student narratives that highlight the benefit of prosocial bystander behavior as well as the knowledge and skills gained through participation in bystander training programs. Based on environmental reevaluation, messaging may focus on the opportunities students have to intervene and the role they can play in preventing sexual violence and/or mitigating its harm (Cares et al. 2015; Potter 2012; Potter et al. 2011).

\section{Limitations and Future Research}

Students have the opportunity to intervene in a wide range of risk situations, and the authors examined just six in this study. Although it is important to consider the full spectrum of situations that students may witness, grouping situations together, as in a previous examination, has the potential to miss differences in students' intervention behavior as well as potential differences between those who do and do not intervene (Banyard 2015). Researchers may consider focusing on commonly reported situations and/or specific intervention behaviors that contribute to primary prevention of sexual assault. Inquiry into students' intervention behavior must also inquire into opportunities as an absence of such cannot differentiate between students who did not intervene out of lack of opportunity rather than lack of prosocial behavior (Banyard 2015; McMahon et al. 2015).

As programmatic activities become more common, even mandated, research should inquire into students' participation in such programs, with items such as those in the Action scale to account for its potential influence on intervention behavior. The specific language of the original RTH items assessing Action, used here, may not accurately capture students' engagement if students conceptualize the mandated training as their participation in activities, however, as Action scores should capture those who are voluntarily seeking out activities or programs on their own rather than mandated training (Banyard et al. 2010). The 
RTH scales do not include the TTM stage of maintenance, which defines those as sustaining engagement in activities that support behavior change for 6 months (Prochaska and DiClemente 1986). Refining RTH scales to include this stage may better capture individuals with greater likeliness of sustaining prosocial bystander behavior as a result of prolonged participation in activities.

The TTM asserts that movement toward later stages of readiness is not linear and individuals could relapse or move backward. Based on recent research that students who report a negative intervention experience report diminished intention to intervene in the future (Krauss et al. 2017; Witte et al. 2017), there is potential for students who have intervened in the past to choose differently in the next opportunity. Banyard and colleagues (2010) hypothesized that RTH precedes bystander behaviors, although the directionality of this assumption was not tested here. Given the nature of crosssectional studies and the inability to discern causal relationships, longitudinal designs would better clarify how students' bystander intervention behavior relates to changing RTH over the course of their college experience. Finally, effect sizes for significant results were small; thus, continued examination of the differences between interveners and noninterveners, with RTH variables or otherwise, is important as the authors further seek to understand salient influences of prosocial behavior.

\section{Conclusions}

Given the vital role bystanders can, and do, play in the prevention of sexual assault and the mitigation of its harm, continued investigation into differences between students who do and do not intervene is warranted. Understanding the nuances of psychosocial differences, as well as the variation between risk situations where students have the opportunity to intervene in, is vastly important in addressing barriers that may keep students from intervening. The utility of the TTM is twofold. Just as the authors can apply the TTM to explain bystander intervention behavior, they can, and should, apply the theory to move students in the general campus population toward participating in the very programming aimed at effectively increasing intervention behavior through specific bystander knowledge, skills, and efficacy.

\section{Author Disclosure Statement}

No competing financial interests exist.

\section{References}

Abbey A, Ross L, McDuffie D, McAuslan P. (1996). Alcohol and dating risk factors for sexual assault among college women. Psychol Women Q. 20, 147-169.

Banyard VL. (2011). Who will help prevent sexual violence: Creating an ecological model of bystander intervention. Psychol Violence. 1, 216-229.

Banyard VL. (2015). Bystander Prevention of Sexual and Relationship Violence: Action Coils to Engage Communities. (Springer International Publishing, New York, NY).

Banyard VL, Eckstein RP, Moynihan MM. (2010). Sexual violence prevention: The role of stages of change. J Interpers Violence. 25, $111-125$.
Banyard VL, Moynihan MM. (2011). Variation in bystander behavior related to sexual and intimate partner violence prevention: Correlates in a sample of college students. Psychol Violence. 1, 287-301.

Banyard VL, Moynihan MM, Cares AC, Warner RA. (2014). How do we know if it works? Defining measurable outcomes in bystanderfocused violence prevention. Psychol Violence. 4, 101-115.

Banyard VL, Moynihan MM, Plante EG. (2007). Sexual violence prevention through bystander education: An experimental evaluation. J Commun Psychol. 35, 463-481.

Banyard VL, Plante EG, Moynihan MM. (2004). Bystander education: Bringing a broader community perspective to sexual violence prevention. J Commun Psychol. 32, 61-79.

Brown AL, Banyard VL, Moynihan MM. (2014). College students as helpful bystanders against sexual violence: Gender, race, and year in college moderate the impact of perceived peer norms. Psychol Women Q. 38, 350-362.

Burn SM. (2009). A situational model of sexual assault prevention through bystander intervention. Sex Roles. 60, 779-792.

Cantor D, Fisher B, Chibnall S, et al. (2015). Report on the AAU Campus Climate Survey on Sexual Assault and Sexual Misconduct. (Westat, Rockville, MD). Retrieved from www.aau.edu/uploaded Files/AAU_Publications/AAU_Reports/Sexual_Assault_Campus_ Survey/AAU_Campus_Climate_Survey_12_14_15.pdf (accessed September 19, 2017).

Cares AC, Banyard VL, Moynihan MM, et al. (2015). Changing attitudes about being a bystander to violence: Translating an inperson sexual violence prevention program to a new campus. Violence Against Women. 21, 165-187.

Coker AL, Cook-Craig PG, Williams CM, et al. (2011). Evaluation of green dot: An active bystander intervention to reduce sexual violence on college campuses. Violence Against Women. 17, 777-796.

DiClemente CC, Doyle SR, Donovan D. (2009). Predicting treatment seekers' readiness to change their drinking behavior in the COMBINE study. Alcohol Clin Exp Res. 33, 879-892.

Edwards RW, Jumper-Thurman P, Pleasted BA, et al. (2002). Community readiness: Research to practice. J Commun Psychol. 28, 291-307.

Gidycz CA, Orchowski LM, Berkowitz AD. (2011). Preventing sexual aggression among college men: An evaluation of a social norms and bystander intervention program. Violence Against Women. 17, 720-742.

Grossbard JR, Mastroleo NR, Geisner IM, et al. (2016). Drinking norms, readiness to change, and gender as moderators of a combined alcohol intervention for first-year college students. Addict Behav. 52, 75-82.

Hoxmeier JC, Acock AC, Flay BR. (2017). Students as prosocial bystanders to sexual assault: Demographic correlates of intervention norms, intentions, and missed opportunities. J Interpers Violence. Advanced Online Publication. DOI: 10.1177/0886260517689888.

Hoxmeier JC, McMahon S, O'Connor J. (2017). Beyond yes or no: Understanding undergraduate students' responses as bystanders to sexual assault risk situations. J Interpers Violence. Advanced online publication. DOI: https://doi.org/10.1177/0886260517723142.

Katz J, Moore J. (2013). Bystander education training for campus sexual assault prevention: An initial meta-analysis. Violence Vict. 28, 1054-1067.

Katz J, Pazienza R, Olin R, Rich H. (2015). That's what friends are for: Bystander responses to friends or strangers at risk for party rape victimization. J Interpers Violence. 30, 2775-2792.

Knight H, Stetson B, Krishnasamy S, Mokshagundam SP. (2015). Diet self-management and readiness to change in underserved adults with type 2 diabetes. Primary Care Diabetes. 9, 219.

Krauss A, Jouriles EN, Yule K, et al. (2017). Adverse consequences to assisting victims of campus violence: Initial investigations 
among college students. J Interpers Violence. DOI: 10.1177/ 0886260517746944.

Latanè B, Darley JM. (1968). Group inhibition of bystander intervention in emergencies. J Pers Soc Psychol. 10, 215-221.

Matwin S, Chang G. (2011). Readiness to change and risk drinking women. J Subst Abuse Treat. 40, 230-240.

McMahon S, Allen CT, Postmus JL, et al. (2014a). Measuring bystander attitudes and behavior to prevent sexual violence. J Am Coll Health. 62, 58-66.

McMahon S, Palmer JE, Banyard V, et al. (2015). Measuring bystander behavior in the context of sexual violence prevention: Lessons learned and new directions. J Interpers Violence. 32, 23962418.

McMahon S, Winter SC, Palmer JE, et al. (2014b). A randomized controlled trial of a multi-dose bystander intervention program using peer education theater. Health Educ Res. 30, 554-568.

Painter JE, Borba CP, Hynes M, et al. (2008). The use of theory in health behavior research from 2000-2005: A systematic review. Ann Behav Med. 35, 358-362.

Potter RH, Krider JE, McMahon PM. (2000). Examining elements of campus sexual violence policies. Violence Against Women. 6, $1345-1362$.

Potter SJ. (2012). Using a multimedia social marketing campaign to increase active bystanders on the college campus. J Am Coll Health. 60, 282-295.

Potter SJ, Banyard VL. (2011). Guest editors' introduction. Violence Against Women. 17, 679-683.

Potter SJ, Moynihan MM, Stapleton JG. (2011). Using social selfidentification in social marketing materials aimed at reducing violence against women on campus. J Interpers Violence. 26, 1-20.

Prochaska JO, DiClemente CC. (1984). The transtheoretical approach: Towards a systematic eclectic framework. (Dow Jones Irwin, Homewood, IL).
Prochaska JO, DiClemente CC. (1986). Toward a comprehensive model of behavior change. In Treating Addictive Behaviors: Processes of Change. WR Miller, N Heather, eds. (Plenum, New York), pp. 3-27.

Pugh B, Ningard H, Vander Ven T, Butler L. (2016). Victim ambiguity: Bystander intervention and sexual assault in the college drinking scene. Deviant Behav. 37, 401-418.

Sherman BJ, Baker NL, McRae-Clark AL. (2016). Gender differences in cannabis use disorder treatment: Change readiness and taking steps predict worse cannabis outcomes for women. Addict Behav. 60, 197-202.

Usala JM, Celio MA, Lisman SA, et al. (2015). A field investigation of the effects of drinking consequences on young adults' readiness to change. Addict Behav. 41, 162-168.

Vander Ven T. (2011). Getting wasted: Why students drink too much and party so hard. (New York University Press, New York).

White House. (2014). Climate surveys: Useful tools to help colleges and universities in their efforts to reduce and prevention sexual assault. Retrieved from www.justice.gov/ovw/page/file/910426/ download (accessed September 19, 2017).

Witte TH, Casper DM, Hackman CL, Mulla MM. (2017). Bystander interventions for sexual assault and dating violence on college campuses: Are we putting bystanders in harm's way? J Am Coll Health. 65, 149-157.

Address correspondence to:

Jill C. Hoxmeier, PhD, MPH, CHES

Department of Health Sciences Central Washington University 400 East University Way, Purser Hall 101 Ellensburg, WA 98926

E-mail: jill.hoxmeier@cwu.edu 